\title{
A Service Platform for RFID Technology Adoption Analysis in Inventory Control
}

\author{
Tianle Zhang \\ Beijing Key Laboratory of \\ Intelligent \\ Telecommunications \\ Software and Multimedia, \\ School of Computer \\ Beijing University of Posts \\ and Telecommunications \\ Beijing, China \\ tlezhang@bupt.edu.cn
}

\author{
Zongwei Luo \\ E-Business Technology \\ Institute \\ the University of Hong \\ Kong \\ Hong Kong, China \\ zwluo@eti.hku.hk
}

\author{
Haifeng Wang \\ Beijing Newcom \\ Technology Co., Ltd. \\ Beijing, China
}

\author{
Yongliang Zhang \\ College of Water \\ Conservancy and Civil \\ Engineering \\ Shandong Agricultural \\ University \\ Taian, China
}

\begin{abstract}
Technology adoption is a practical exercise for technology and innovation management. Adopting an innovative technology often requires extensive intelligence research due to multi-perspectives towards technologies. In this paper, we present an implementation of a service platform for enabling such technology adoption analysis. The design principles for the service platform are proposed to identify value indicators for perceived value evaluation for RFID technology adoption analysis. An illustration is presented to demonstrate how to identify value indicators in facilitating RFID adoption in inventory control.
\end{abstract}

Keywords- RFID; SCOR model; Technology adoption; Service platform; Inventory Control

\section{INTRODUCTION}

In today's interconnected business world, evolving in the global trend of modernization, supply chain and logistics management, as one of the fundamental enablers for ebusiness, is being re-invented to play an even more important role. The efficiency of the supply chain has a direct impact on a company's profitability potential. It is no surprise therefore to find that many large corporate companies have made it a key part into their business strategy, and invested heavily in software systems and IT infrastructure designed to control inventory, track products, etc.

Recently, RFID emerges to be a promising technology to revolutionize the supply chain and logistics management, along with the unprecedented explosion in wireless networking technologies. These technologies are expected to co-exist to form a wireless environment enabling modern logistics and supply chain management. These new wireless paradigms will further drive the way for innovative services and applications in logistics and supply chain applications. In the meantime, it is certainly necessary to conduct technology evaluation in adopting these technologies while developing business opportunities. Thus, there demand decision support tools for technology adoption in supply chain and logistics management, to filter, pick, and deploy the technologies that can drive for business value.

In this paper, we will focus the study on technology adoption in supply chain and logistics management. A service platform for technology adoption analysis is proposed and implemented to help enterprises to make a decision on adopting enabling technologies such as RFID. As an illustration, we will present an example for analyzing RFID technology adoption in inventory to identify value indicators for perceived value evaluation. Organization of the paper is as follows: In Section II, an overview for related work is given. In Section III, the technology analysis framework is presented. Section IV is the design principles for the analysis platform. In Section V, we present the system implementation of the analysis platform. In Section VI, an illustration is presented to demonstrate how to identify value indicator for facilitating RFID adoption in inventory control. Section VII concludes the paper with summarization on key findings.

\section{RELATED WORK}

Several theories, such as Diffusion of Innovation theory [1], the Technology Acceptance Model [2], the Theory of Reasoned Action [3], the Theory of Planned Behavior [4], and Social Cognitive Theory [5] etc., have been developed to explain adoption and acceptance of technologies. Among these theories, Rogers' diffusion of innovation (DOI) [1] theory and Davis' Technology Acceptance Model (TAM) [2] have received significant attention. TAM and DOI are quite similar in terms of identifying the perceived attributes of an innovation as key predictors explaining adoption. DOI, which was derived from a variety of studies on different innovations, identifies five perceived attributes influencing the rate of adoptions. It also includes other attributes in the society that can influence 
innovation diffusion, such as incentives and mandates. While TAM, created specifically to explain IT adoption, proposes just two perceived attributes that influence adoption (usefulness and ease-of-use). There are many diffusion of innovation (DOI) research reported in [6]. Most of them investigate the evaluation, adoption, and implementation of innovations. In DOI, characteristic of the five categories are identified and are captured as below:

- Innovators: Venturesome gatekeepers of the diffusion process. They have high mass media exposure, and can often use their communication channels to reach out into their local system.

- Early Adopter: Respectable people who are a closer integrated part of the local social system than innovators. They have the highest leadership opinion since potential adopters look to early adopters for advice and information about the innovation.

- Early Majority: Deliberate people who adopt new ideas just before the average member of a local social system. Their innovation-decision period is relatively longer than that of the innovators and the early adopters.

- Late Majority: Skeptical people who adopt new ideas just after the average member of the system. Adoption may be both an economic necessity for the late majority and the result of increasing peer pressures.

- Laggards: The last in a social system to adopt the innovation who are suspicious of it.

From the DOI adopter categories, it can be identified that significant determinants of technology adoption models vary from technology to technology and suitable models are case by case [7]. It can also be inferred that the effect of technological changes also varies on different experience groups with different learning initiatives [8]. Usage models as well as culture are also one of the key adoption enablers for technology adoption [9, 10]. Recognizing the diversified models of network technology adoption, research in [11] tried to understand the inter-dependent adoption dynamics and heterogeneity in an equilibrium setting. In [10] the heterogeneity was expressed by differences in adoption costs, network effects, and tastes for a diverse network. Such differences would actually affect the network technology diffusion and use [10].

\section{ADOPTION ANALYSIS METHDOLOGY}

In this paper, we propose to identify value indicators (e.g. cost, lead time, etc.) which can be used for evaluating perceived values for adoption analysis. The value indicators serve as value metrics to evaluate perceived value from different adoption parties. Value indicators are often strongly associated with adoption models, analysis scope, and value evaluation. During the adoption analysis, the value indicators are processed within an analysis boundary or scope.

As market participants exchange goods/services in the market, they are seeking what they need, the classical demand and supply relationship. The value of the goods or services is often expressed as financial dollars or rewards in many forms. Technology adoption is no exception to that. DOI has pointed out five different perceived attributes influencing the rate of adoptions. Research has also showed that there exist gaps among values perceived from different parties in the adoption, e.g. technology provider, technology user, etc. Value compatibility becomes one of the key issues for investigating adoption, diffusion and success among different parties in adoption. In [12], group values and practical compatibility were found to be a facilitator of successful adoptions.

In the case for analyzing RFID technology adoption in logistics and supply chain management, the value indicators often relate to metrics indicating its value whether the supply chain visibility can translate into actions to improve supply chain operation efficiency and to reduce cost. While the potential promised by the RFID technology is eminent for logistics and supply chain management, the adoption level very much counts on the perceived value by the different adoption parties. The perceived values are explained as follows as identified in DOI:

- Relative advantage is a ratio of the expected benefits and the costs of adoption of an innovation. In the case of RFID adoption analysis, the value proposition of RFID in inventory control are observable as: 1) Increases in order fulfillment rate and customer loyalty, 2) reduction in inventory keeping cost and warehousing and delivery labor, and 3) cost avoidance in Labor (Counting, data collection), inventory surveillance, and report.

- Compatibility is the key point to a successful adoption of an innovation. Compatibility for RFID in inventory control could be expressed by technology interoperability (server, database, tag, readers, and standards), and practice interoperability (RFID system deployment and maintenance).

- The complexity of an innovation, as perceived by potential adopters, is negatively related to its rate of adoption. The complexity of RFID adoption in inventory control could be split into two sections: the complexity of the RFID deployment and the complexity of operating RFID systems.

- Trialability is the degree to which an innovation may be experimented with on a limited basis. High initial cost of RFID system prevents the trial of applying RFID in retailers. Thus it is necessary to help potential adopters with an intuitive sense of applying RFID with a pilot system package.

- Observability is the degree to which the results of an innovation are visible to others. RFID can help to increase order fulfillment rate and customer loyalty, reduction in inventory keeping cost and cost avoidance in labor, inventory surveillance, and reporting.

This analysis methodology can help identify how RFID could bring value to supply chain management. While the whole chain could be analyzed for adoption potentials, the analysis could be conducted on different segments of the 
supply chain to evaluate individually how each can take advantage of RFID technology. It is expected that there exist inter-play among different chains. For example, retailers piloting RFID programs report improved sales from greater stock availability, cost savings and increased responsiveness, especially in receiving and inventory control operations. As these applications continue to prove their value, more retailers are expected to announce compliance tagging requirements, so many manufacturers may find themselves being asked or required by a retail customer to apply RFID tags to shipments. Researchers may expect that RFID could be applied through the whole supply chain from raw material suppliers to end retailers.

\section{DESIGN PRINCIPLES}

In order to obtain good value indicators for perceived value evaluation, based on the proposed analysis methodology, we will implement a service platform for technology adoption analysis to facilitate the indicator identification. Design principles for such an analysis service platform are demand driven, context driven and process driven.

\section{A. Demand driven}

To cope with various needs for business decision making in technology adoption, there are many analysis models and tools, e.g. ROI, category analysis, developed. All these models focus on specific aspects of decision-makings. Although some of these analysis models or tools consider inputs from multidimensional perspective. They seldom span from IT system analysis to business culture analysis. Thus, for an informed decision making, and to address the analysis gaps existing in current decision making tools, we have to develop an analysis tool providing a holistic view for business analysis. This holistic view has to meet the demand from technology adoption analysis needs.

\section{B. Context driven}

The adoption analysis has to be conducted in a right context to supply necessary data input for analysis. For example, if there is a case to analyze RFID technology adoption in supply chain management, then the context is within supply chain management. The design principle of reference model driven would then require a selection of a reference model for logistics and supply chain management. The Supply Chain Operations Reference-model (SCOR) [13], developed by the Supply-Chain Council (SCC) provides a unique framework that links business process, metrics, best practices and technology features into a unified structure to support communication among supply chain partners and to improve the effectiveness of supply chain management and related supply chain improvement activities. It forms a good reference model for conducting RFID technology adoption analysis in logistics and supply chain management.

The SCOR-model has been developed to describe the business activities associated with all phases of satisfying a customer's demand. The model itself contains several sections and is organized around the five primary management processes of Plan, Source, Make, Deliver, and Return. By describing supply chains using these process building blocks, the SCORE model can be used to describe supply chains that are very simple or very complex using a common set of definitions. As a result, disparate parties can be linked to describe the depth and breadth of virtually any supply chains.

\section{Process driven}

There are many tools and models developed for business analysis. SWOT Analysis is an often used one for it provides a satisfactory business view by balancing the analysis efforts and the analysis coverage. In the market, we often have to use several analysis tools together. Thus, understanding the relationship among various analysis tools and models is the key for an integrated analysis. The relationships could be complex though. The relationship could link to the processes of applying the models and tools, besides their apparent usage association in inputs and output. For example, Return on Investment (ROI) and Total cost of ownership (TCO) provide quite similar analysis. Typical TCO analysis provides the control function and intends to reduce the risk in capital investment. ROI analysis evaluates the potential results by the initial Investment. Through it, companies can calculate the return rate of the new projects or products.

The other example is Product concept test and need assessment. Product concept test provides evaluation analysis to bring a new product into market. Need assessment finds the needs out from the market. Companies often don't use them at the same time. Companies often use the need assessment to explore the potentials of the market. Out of the results if any potential existing, companies would go on to design and develop a new set of products. Of course, these new set of products are designed to fulfill the needs of the market. Thus, once the new products concept is developed, companies can manufacture some sample products. After that, companies can test try the product to the market. The product acceptance from the market would then be observed. The higher the sales volume is, the higher the acceptance is. It is mean that users or customers are satisfied the needs by using this new product.

The relationship among different analysis tools and models would put them in order in the analysis processes. However, the ordering could change and adapt to various analysis needs and personal habits. For example, business students start to learn the analysis sequence in their classrooms led by their business school professors. The ordering also depends on the analysis results from each tool, i.e. we have to perform one analysis to derive results before we can perform a next analysis.

Next, we will introduce system implementation for an analysis platform that leverages various analysis tools for adoption analysis based on these design principles.

\section{SYSTEM IMPLEMENTATION}

The analysis service platform helps the enterprises to make a decision on adopting RFID and its applications. It examines RFID adoption impact along supply chain based on activities referring to SCOR model and identifies the metrics of measuring the performance of supply chain. 


\section{A. System architecture}

The service platform would help bring together various models and tools to label an enterprise with a right adopter name according to DOI and identify variables influencing the rate of RFID adoption apply for all the enterprises. We may also filter and obtain the important variables to analyze the RFID adoption traceable path and obtain ways for adoption analysis speedup. Through identifying parameters for describing the value perception, a service platform based on value analysis will be developed to prioritize those parameters and mark those most important parameters as value indicators (e.g. cost, lead time, etc.) which can be used for perceived value analysis in adoption. The architecture of this service framework is shown in Figure 1.

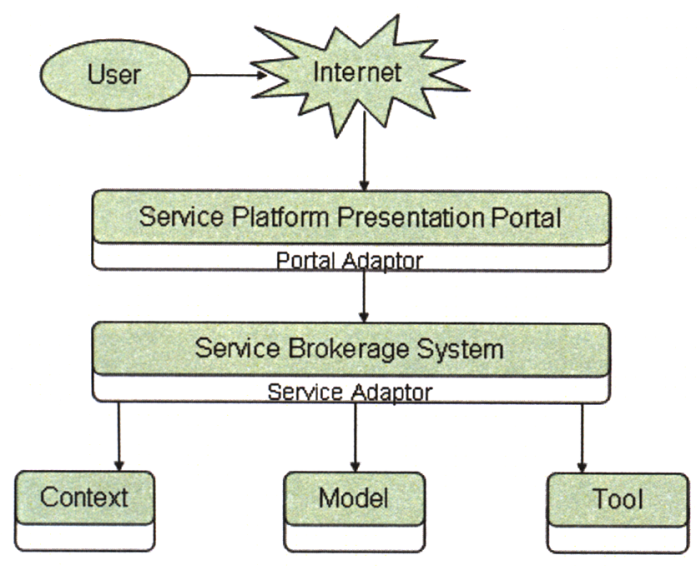

Figure 1. Technology Adoption Analysis Service Platform

As shown in Figure 1, the technology adoption analysis service platform (the service platform) is constructed based on on-demand services infrastructure - the service brokerage infrastructure. It provides technology analysis provisioning services for orchestrating data, application and execution facilities like clusters, or desktop PCs. The data services are responsible for data access including data gathering, loading and transformation. Application services are responsible for application access. Execution services provide functions to access computing facilities. Various business intelligence services including data mining and knowledge discovery would be available in this platform.

The key functional components in this service platform are the context analysis, model analysis, and tool analysis. They together provide services to identify value indicators to evaluate perceived value from different technology adoption parties. To cope with various needs for business decision making in technology adoption, the context analysis help set a right context to supply necessary data input for adoption analysis. The SCOR model provides a good reference for conducting RFID adoption analysis in logistics and supply chain management. Model analysis will help select right analysis models and identify the relationship among different analysis models and put them in order in the analysis processes. Tool analysis will help provide an integrated tooling to perform adoption analysis.

\section{B. Operation models}

The service brokerage infrastructure will help form a right analysis process according to demanded technology adoption analysis. The analysis process will take input relevant to the potential adopter's businesses to derive value indicators. Like other business intelligence, statistical and benchmarking exercises, the analysis data input to the service platform has great impact on the adoption analysis results. The technology adoption analysis process would involve multiple parties for multi-party collaborations. To suite different operating behavior of each participating party, the service platform provides two operation models, i.e. online participation and offline participation. These two types of operation models will help address the concerns about protecting the privacy of individuals as well as companies' trade secret involved in the adoption analysis. Towards this, the two service models are developed in this service platform:

- Online participation: in this way, participants login to the service platform portal and load data to the tools in the service platform to conduct adoption analysis.

- Offline participation: in this way, the technology adoption analysis tools are downloaded to the local environment of the platform participants. When these participants process their analysis data, it is not necessary for them to upload their data into service platform.

\section{Analysis processes}

To construct the adoption analysis, we have to form a right analysis process to link up the context, analysis models, and tools for value indicator identification. An example of such a process [14] is as follows. In this analysis process, it will first conduct needs assessment for RFID. Once the need is confirmed positive, next step would be the SWOT analysis from which an initial plan for RFID adoption would be derived. After finishing the Risk management or ROI/TCO analysis, there would be a set of analysis in the three parallel paths. Category Awareness and Category Viability Assessment will be one of the three. If the category is not the best, decisions could be made as to limit the scope of the RFID introduction or terminate RFID introduction. Early Adopter Indentation and Adoption Curve Placement is the second path in the analysis process. This will help to identify the early adopter of the RFID technology. Product Concept Testing is the third path in the analysis process. From this analysis, most important information like the testing result of the market would be known.

\section{AN ILLUSTRATION}

So far, we have described a service platform for technology adoption analysis. To illustrate the feasibility of this service platform, a process is constructed for identifying value indicators for perceived value analysis. An analysis process involving the following steps (see Figure 2) for analyzing RFID adoption in inventory control is formed. SCOR model is 
selected as reference model. Various analysis models and tools are made available in conducting the analysis process.

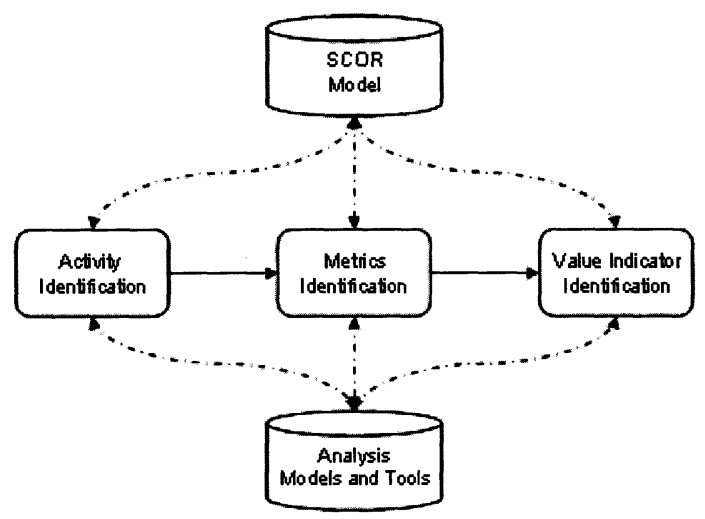

Figure 2. RFID adoption analysis process in inventory control

\section{A. Activity identification}

According to the interaction and relationship among the activities defined in SCOR model, we first classify them into different categories, based on the criteria whether RFID adoption would lead any potential impact on them. The activity categories are identified in TABLE I, including product tracking, receiving \& shipping, asset management, inventory control, packaging, shelf management and check out, data collection, regulation and customer requirement compliance, and returns management.

From these activity categories, we would further identify value activities which have direct RFID impacts, shown in TABLE I. For example, in Inventory control category, there are activities like ES.4 Manage Product Inventory, D4.1 Generate Stocking Schedule, and ED.4 Manage Finished Goods Inventories. These activities are identified because real time RFID data could potentially lead to timely information for managing various inventories, either to reduce the inventory level or the lead time to generating stocking schedules.

TABLE I. ACTIVITY CATEGORIES AND VALUE ACTIVITIES

\begin{tabular}{|c|c|}
\hline Category & Activity \\
\hline \multirow[t]{6}{*}{ Production Tracking } & M1.2/M2.2/M2.3 Issue Material \\
\hline & M1.3/M2.3/M3.4 Produce and Test \\
\hline & M1.5/M2.5/M3.6 Stage Product \\
\hline & EM.4 Manage In-Process Products (WIP) \\
\hline & EM.6 Manage Transportation \\
\hline & EM.7 Manage Production Network \\
\hline \multirow{8}{*}{$\begin{array}{l}\text { Receiving \& } \\
\text { Shipping }\end{array}$} & S1.2/S2.2/S3.2 Receive Product \\
\hline & S1.3/S2.3/S3.3 Verify Product \\
\hline & S1.4/S2.4/S3.4 Transfer Product \\
\hline & ES.6 Manage Incoming Product \\
\hline & $\begin{array}{c}\text { D1.8/D2.8/D3.8 Receive Product from Source } \\
\text { or Make }\end{array}$ \\
\hline & D1.9/D2.9/D3.9 Pick Product \\
\hline & D1.12/D2.12/D3.12 Ship Product \\
\hline & D4.2 Receive Product at Store \\
\hline Asset management & EM.5 Manage Equipment and Facilities \\
\hline
\end{tabular}

\begin{tabular}{|c|c|}
\hline & ED.5 Manage Deliver Capital Assets \\
\hline \multirow[t]{3}{*}{ Inventory Control } & ES.4 Manage Product Inventory \\
\hline & D4.1 Generate Stocking Schedule \\
\hline & ED.4 Manage Finished Goods Inventories \\
\hline \multirow[t]{2}{*}{ Packaging } & M1.4/M2.4/M3.5 Package \\
\hline & D1.10/D2.10/D3.10 Pack Product \\
\hline \multirow{3}{*}{$\begin{array}{c}\text { Shelf Management \& } \\
\text { Check Out }\end{array}$} & D4.3 Pick Product from Backroom \\
\hline & D4.4 Stock Shelf \\
\hline & D4.6 Checkout \\
\hline \multirow[t]{6}{*}{ Data Collection } & $\begin{array}{c}\text { P4.1 Identify, Prioritize, and Aggregate } \\
\text { Delivery Requirements }\end{array}$ \\
\hline & ES.2 Assess Supplier Performance \\
\hline & ES.3 Maintain Source Data \\
\hline & $\begin{array}{l}\text { D1.11/D2.11/D3.11 Load Vehicle \& Generate } \\
\text { Shipping Documentation }\end{array}$ \\
\hline & ED.2 Assess Delivery Performance \\
\hline & ED.3 Manage Deliver Information \\
\hline \multirow{3}{*}{$\begin{array}{l}\text { Regulatory and } \\
\text { Customer } \\
\text { Requirement } \\
\text { Compliance }\end{array}$} & ES.8 Manage Import/Export Requirements \\
\hline & EM.8 Manage Regulatory Compliance \\
\hline & ED.8 Manage Import/Export Requirements \\
\hline \multirow[t]{3}{*}{ Returns Management } & DR1.3 Receive Defective Product \\
\hline & DR2.3 Receive MRO Product \\
\hline & DR3.3 Receive Excess Product \\
\hline
\end{tabular}

\section{B. Metrics identification}

Metrics for the inventory control include Cost to Manage Inventory, etc. (see TABLE II). A general type of metrics is also defined for evaluating the RFID system in reliability, complexity, user friendly and durability in harsh environment. These metrics exist in the whole supply chain (i.e. in every activity impacted by RFID adoption), so we group them in a general category.

TABLE II. METRICS IN INVENTORY CONTROL

\begin{tabular}{|c|c|}
\hline Metrics & Description \\
\hline $\begin{array}{l}\text { Cost to Manage } \\
\text { Inventory }\end{array}$ & $\begin{array}{l}\text { The sum of the costs associated with } \\
\text { inventory control activities. }\end{array}$ \\
\hline $\begin{array}{l}\text { Manage Inventory Cycle } \\
\text { Time }\end{array}$ & $\begin{array}{l}\text { The average time associated with } \\
\text { inventory control activities. }\end{array}$ \\
\hline Goods Inventory Days & $\begin{array}{l}\text { The average of the sum of all gross } \\
\text { inventories. Total gross value of inventory } \\
\text { at standard cost before reserves for excess } \\
\text { and obsolescence. }\end{array}$ \\
\hline $\begin{array}{l}\% \text { of Orders Delivered in } \\
\text { Full }\end{array}$ & $\begin{array}{l}\text { Percentage of orders which all of the items } \\
\text { are received by customer in the quantities } \\
\text { committed. }\end{array}$ \\
\hline Theft lost & $\begin{array}{c}\text { The sum of lost associated with theft } \\
\text { crime. }\end{array}$ \\
\hline
\end{tabular}

\section{Value indicator identification}

From the above table, we select the attributes which have direct or non-negligible impact on the revenue of the enterprises. We identify which can increase revenue, which can reduce costs and which can avoid costs and group them as the benefits that are brought by RFID adoption. For example, there exist one-time and recurring costs of installing and maintaining an RFID system. In the case of inventory control, the benefits, costs and risks will include the following as shown in TABLE III. These metrics in TABLE III are called value indicators for RFID adoption in inventory control. The benefits and costs, as 
long as the risks, will facilitate the further ROI analysis for perceived value evaluation.

TABLE III. BENEFITS, COST AND RISKS

\begin{tabular}{|c|c|}
\hline Benefits & \begin{tabular}{ll} 
& \multicolumn{1}{c}{ Increase in revenue: } \\
- & Increased order fulfillment rate \\
- & Increased customer loyalty \\
Reduced cost: \\
- & \multicolumn{1}{c}{ Inventory keeping cost } \\
- & Warehousing and delivery labor \\
Avoided cost: \\
- \\
- \\
Labor (Counting, data collection) \\
- $\quad$ Report \\
\end{tabular} \\
\hline Cost & \begin{tabular}{ll} 
& \multicolumn{1}{c}{ One time cost: } \\
- & Server \\
- & Database \\
- & Deployment \\
- & Project management \\
- & Readers and other hardware \\
$\quad$ & Recurring cost: \\
- & Tags \\
- & System administration \\
- & Maintenance and development \\
\end{tabular} \\
\hline Risks & \begin{tabular}{ll} 
& \multicolumn{1}{c}{ Internal risk: } \\
- & Inaccurate data \\
- & External risk: \\
Immaturity of standards
\end{tabular} \\
\hline
\end{tabular}

\section{CONCLUSION}

Value perception is the key for RFID adoption. In order to obtain good value indicators for perceived value evaluation, based on the proposed analysis methodology, we implement a service platform for technology adoption analysis to facilitate the indicator identification. Design principles for such an analysis service platform are demand driven, context driven and process driven.

In order to identify the value of RFID adoption in inventory control, as an illustration, the implementation of our methodology in an analysis service platform first examines the whole supply chain based on the classical supply chain model - SCOR model. It helps build a reference model to obtain indepth insight into the multi-level supply chain. We did a comprehensive study on SCOR model to see which activities can be improved by applying RFID and classified these activities into several categories considering their relationship and interactions. We also built a metrics repository for each activities category to aid the adoption analysis. This can help the supply chain players to determine what category is suitable for them to apply RFID according to their own business characteristics. Then, based on the features of RFID technology we identify the metrics for assessing the values for introducing RFID into the inventory control activities. We identified the benefits, costs and risks of RFID adoption in inventory control, as an illustration.

\section{REFERENCES}

[1] Rogers, Everentt M. Diffusion of innovations, 5th ed., The Free press, 2003.

[2] F.D. Davis, "Perceived usefulness, perceived ease-of-use and user acceptance of information technology," MIS Quarterly, Vol. 13, No. 3, pp. 319-339.

[3] I. Ajzen, M. Fishbein, Understanding Attitudes and Predicting Behavior, Englewood Cliffs, NJ: Prentice-Hall

[4] I. Ajzen, "From intentions to action: a theory of planned behavior," Action control: from cognition to behavior, J. Kuhl and J.Beckmann (Eds), New York: Springer-Verlag, pp. 11-39.

[5] D.R. Compeau, C.A. Higgins, "Application of social cognitive theory to training for computer skills," Information Systems Research, Vol. 6, No. 2, pp. 118-143.

[6] Mary B. Prescott, Sue A. Conger, "Information technology innovations: a classification by it locus of impact and research approach," ACM SIGMIS, 1995.

[7] Matthew L. Nelson, Michael J. Shaw, Adoption of Technology Standards in Supply Chains: A Case of Adopting RosettaNet Standards, DIGIT, 2001 IT Adoption \& Diffusion Workshop, Dec 16, 2001.

[8] Bruce A. Weinberg, Experience and Technology Adoption, February 2005

[9] Intel Corp., Community-Based Technology Adoption: Research at Intel, Intel white paper, 2006.

[10] Poku, K., Vlosky, R. P., A Model of the Impact of Corporate Culture on Information Technology Adoption, Working Paper \#57, Louisiana Forest Products Laboratory, Louisiana State University Agricultural Center, Baton Rouge, LA, December 2, 2002

[11] Ryan, S. and Tucker, C., Heterogeneity and the Dynamics of Technology Adoption, MIT working paper, October 4, 2006

[12] Susan J. Harrington, Cynthia P. Ruppel, Practical and value compatibility: their roles in the adoption, diffusion, and success of telecommuting, Proceeding of the 20th international conference on Information Systems, Charlotte, North Carolina, 1999, pp. 103-112.

[13] Supply-Chain Council, Supply Chain Operations Reference Model SCOR Version 8.0, 2006

[14] Z. Luo, et al. Apply Model Integration in RFID Technology Adoption Analysis, IEEE ICAL, 2007. 